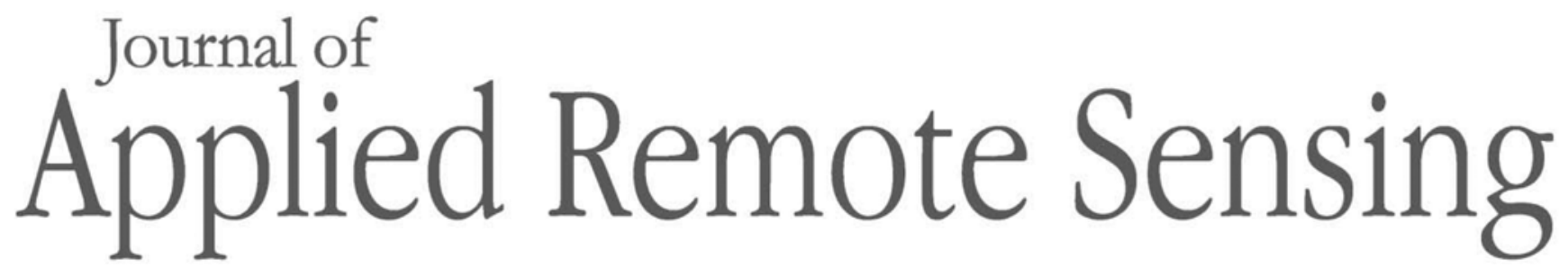

RemoteSensing.SPIEDigitalLibrary.org

\title{
Integrative image segmentation optimization and machine learning approach for high quality land-use and land-cover mapping using multisource remote sensing data (Erratum)
}

Mohamed Barakat A. Gibril Mohammed Oludare Idrees

Kouame Yao

Helmi Zulhaidi Mohd Shafri 


\title{
Integrative image segmentation optimization and machine learning approach for high quality land-use and land-cover mapping using multisource remote sensing data (Erratum)
}

\author{
Mohamed Barakat A. Gibril, ${ }^{\text {a,b }}$ Mohammed Oludare Idrees, ${ }^{a}$ \\ Kouame Yao, ${ }^{\text {a,c }}$ and Helmi Zulhaidi Mohd Shafri ${ }^{\mathrm{a}}$ \\ ${ }^{a}$ Universiti Putra Malaysia, Department of Civil Engineering, Faculty of Engineering, \\ Serdang, Selangor Darul Ehsan, Malaysia \\ ${ }^{b}$ University of Prince Mugrin, Department of Civil Engineering, College of Engineering, \\ Madinah, Saudi Arabia \\ ${ }^{c}$ Macquarie University, Department of Earth and Planetary Sciences, \\ Faculty of Science and Engineering, North Ryde, Australia
}

This article [J. Appl. Remote Sens. 12(1), 016036 (2018)] contained a misspelling of the name of the third author, Kouame Yao, when it was published on March 9, 2018. All online versions of the article were corrected on 13 March 2018.

(C) 2018 Society of Photo-Optical Instrumentation Engineers (SPIE) 